\title{
Хроматографические и экстракционные свойства ацетонитрила и его смесей с водой
}

\author{
Рудаков О.Б. ${ }^{1}$, Селеменев В.Ф. ${ }^{2}$, Рудакова Л.В. ${ }^{3}$, Подолина Е.А. ${ }^{4}$ \\ ${ }^{1}$ ФГБОУ ВО «Воронежский государственный технический университет», Воронеж \\ ${ }^{2}$ ФГБОУ ВО «Воронежский государственный университет», Воронеж \\ ${ }^{3}$ ФГБОУ ВО «Воронежский государственньй медииинский университет им. Н.Н. Бурденко», \\ Воронеж \\ ${ }^{4}$ ФГБОУ ВО «Государственный гуманитарно-технологический университет», Орехово-Зуево
}

Поступила в редакцию 30.05.2018 г.

DOI: https://doi.org/10.17308/sorpchrom.2018.18/554

В обзоре рассмотрены хроматографические и экстракционные свойства ацетонитрила и его смесей с водой. Обсуждено влияние состава смесей ацетонитрил - вода на такие свойства как плотность, вязкость, коэффициент проницаемости, показатель преломления, оптическая плотность, температура кипения. Рассмотрено применение обобщенного критерия полярности ацетонитрила в оценке элюирующей способности подвижных фаз на основе смесей ацетонитрила с водой. Показаны преимущества и проблемы применения ацетонитрила как модификатора подвижной фазы в обращенно-фазовой ВЭЖХ и как гидрофильного экстрагента в жидкостно-жидкостной экстракции.

Ключевые слова: ацетонитрил, вода, обращенно-фазовая ВЭЖХ, жидкостно-жидкостная экстракция, экстракционное вымораживание

\section{Chromatographic and extraction properties of acetonitrile and mixtures of acetonitrile with water}

\author{
Rudakov O. B. ${ }^{1}$, Selemenev V.F. ${ }^{2}$, Rudakova L.V. ${ }^{3}$, Podolina E.A. ${ }^{4}$ \\ ${ }^{1}$ Voronezh state technical University, Voronezh \\ ${ }^{2}$ Voronezh state University, Voronezh \\ ${ }^{3}$ Voronezh state medical University, Voronezh \\ ${ }^{4}$ State humanitarian and technological University, Orekhovo-Zuyevo
}

In 2018 the scientific community celebrates 115 years of discovery of the liquid chromatography method by M.S. Tsvet, and also 50 years since the development of the high-performance liquid chromatography method. The key component of the chromatographic sorbent-sorbate-eluent system, whose optimization is devoted to the authors' studies of the article, is the eluent. High-performance liquid chromatography has become an important method of analysis over the past decades. Acetonitrile is a unique solvent for chromatography. It is used as the main component for water-organic mobile phases in reversed-phase and hydrophilic HPLC. The review discusses the features of its physicochemical properties which should be taken into account in analytical practice. Effective methods of sample preparation are required for the analysis of biologically active substances in different matrices using HPLC. Methods of liquid-liquid extraction (LLE) of analytes from aqueous solutions with salting out and drying out; micro-LLE; dispersive micro-LLE, lowtemperature LLE, extraction by freezing, combined sorption-extraction method QuEChERS are considered. Acetonitrile is used for each of these sample preparation methods. The review discusses the effect of the composition of acetonitrile-water mixtures on such properties as density, viscosity, permeability coefficient, refractive index, optical density, boiling point. The relative polarity, eluting and solubilizing ability of aceto- 
nitrile is considered. The advantages and problems of using acetonitrile as a modifier of the mobile phase in reversed-phase HPLC and as a hydrophilic extractant in liquid-liquid extraction.

Keywords: acetonitrile, water, reversed-phase HPLC, liquid-liquid extraction, extraction freezing

\section{Введение}

В 2018 году мировое научное сообщество отмечает 115-летие открытия русским ученым М.С. Цветом жидкостной хроматографии. Уже 50 лет этот метод применяется в виде ВЭЖХ, который, оставаясь базовым методом анализа самого широкого спектра органических соединений, развился до ультраэффективной жидкостной хроматографии (УЭЖХ)[1]. Благодаря совокупности физико-химических свойств, ацетонитрил занял лидирующие позиции среди растворителей в хроматографическом анализе и исследованиях, связанных с разработкой методов разделения (Separation Science). Так, смеси ацетонитрила с водой - основные элюенты в обращеннофазовой и гидрофильной ВЭЖХ. Эти варианты ВЭЖХ закрывают до 70\% применений хроматографического анализа.

Авторы посвящают эту статью подведению итогов своего 20-летнего исследования специфики хроматографических и экстракционных свойств ацетонитрила $(\mathrm{MeCN})$ и его смесей с водой.

$\mathrm{MeCN}$ - апротонный умеренно полярный органический растворитель. До внедрения обращенно-фазовой (ОФ) ВЭЖХ в 80-х годах прошлого века в широкую аналитическую практику он имел ограниченное применение в химической и фармацевтической технологии. Целый ряд уникальных свойств MeCN привел к тому, что он стал практически незаменимым аналитическим растворителем и нашел самое широкое применение в оптических методах анализа, в ОФ ВЭЖХ, в капиллярном электрофорезе, в самых различных методах подготовки проб [1-8].

В монографиях [3-5], посвященных растворителям для ВЭЖХ, приводится следующий перечень характерных свойств, обуславливающих активное применение $\mathrm{MeCN}$ :

1) обладает умеренной полярностью;

2) проявляет превосходную солюбизирующую способность;

3) его применение в составе элюентов, как правило, характеризуется четкими хроматографическими пиками сорбатов;

4) хорошо смешивается не только с водой, но и большим количеством органических растворителей;

5) его смеси с водой имеют, в отличие от смесей спиртов и эфиров с водой, низкую вязкость;

6) является слабым акцептором водородной связи;

7) имеет маскимально низкое среди других растворителей значение порога прозрачности в УФ-спектре (только особо чистый $\mathrm{MeCN}$ );

8) с водой при низких температурах (ниже $-1^{\circ} \mathrm{C}$ ) образует двухфазные жидкие системы [7-12], что можно использовать в жидкостно-жидкостной экстракции (ЖЖЭ).

В работах [3-7] были отмечены и некоторые негативные характеристики $\mathrm{MeCN}$ :

1) фосфатные буферы, особенно многозарядные рН-буферы, весьма ограниченно растворимы в $\mathrm{MeCN}$;

2) МeCN химически не инертен, медленно гидролизуется, реагирует с сильными кислотами, например с серной кислотой;

3) токсичен; 
4) особо чистый $\mathrm{MeCN}$, пригодный для УФ-спектрофотометрии и ВЭЖХ-УФ, является одним из самых дорогих растворителей, применяемых в больших количествах в подготовке проб и хроматографическом анализе.

Не смотря на приведенный выше перечень негативных свойств $\mathrm{MeCN}$, его положительные свойства перевешивают. Найти полноценную замену этому растворителю в хроматографическом анализе с применением ОФ ВЭЖХ не удается.

\section{Хроматографические свойства ацетонитрила и его смесей с водой}

В табл. 1 приведены основные технические требования к хроматографическим растворителям и дана экспертная оценка соответствия ацетонитрила этим требованиям по пятибалльной шкале [14]. Для подтверждения этих оценок в табл. 2-4 даны количественные характеристики типичных растворителей для ОФ ВЭЖХ [2-6, 14].

Таблица 1. Экспертная оценка $\mathrm{MeCN}$ марки «для ВЭЖХ» по основным физикохимическим и техническим параметрам

\begin{tabular}{|c|c|c|c|}
\hline Параметр & Требования & Факторы & Баллы \\
\hline Температура кипения & $\begin{array}{l}\text { Достаточно } \\
\text { высокая }\end{array}$ & $\begin{array}{c}\text { Для предотвращения: образования паровых } \\
\text { пузырей, мешающих работе клапанов насоса и } \\
\text { детекторов; для минимизации изменения со- } \\
\text { става элюента из-за испарения низкокипящего } \\
\text { компонента } \\
\end{array}$ & 5 \\
\hline Плотность & $\begin{array}{l}\text { Достаточно } \\
\text { высокая }\end{array}$ & $\begin{array}{c}\text { Более плотные элюенты требуют меньшей вы- } \\
\text { соты напора над входом в насос, для них менее } \\
\text { вероятен турбулентный тип потока }\end{array}$ & 5 \\
\hline Вязкость & Низкая & $\begin{array}{c}\text { В низковязких элюентах эффективней протека- } \\
\text { ет диффузия и массообмен, меньше рабочее } \\
\text { давление насоса }\end{array}$ & 5 \\
\hline $\begin{array}{l}\text { Поглощение в УФ } \\
\text { области спектра }\end{array}$ & Низкое & $\begin{array}{l}\text { Заметное поглощение элюента ухудшает чув- } \\
\text { ствительность спектрофотометрического де- } \\
\text { тектора }\end{array}$ & 5 \\
\hline $\begin{array}{l}\text { Показатель прелом- } \\
\text { ления } \\
\end{array}$ & Низкий & $\begin{array}{l}\text { Высокий показатель преломления ухудшает } \\
\text { чувствительность рефрактометрического де- } \\
\text { тектора } \\
\end{array}$ & 5 \\
\hline $\begin{array}{l}\text { Химическая ста- } \\
\text { бильность }\end{array}$ & Высокая & $\begin{array}{l}\text { Для того, чтобы не использовать стабилизато- } \\
\text { ры, для избегания дрейфа времен удерживания }\end{array}$ & 4 \\
\hline $\begin{array}{l}\text { Химическая инерт- } \\
\text { ность }\end{array}$ & Высокая & $\begin{array}{c}\text { Для предотвращения взаимодействия с анали- } \\
\text { том, для избегания модификации сорбентов и } \\
\text { сорбатов }\end{array}$ & 3 \\
\hline Чистота & $\begin{array}{c}\text { Отсутствие } \\
\text { летучих и } \\
\text { нелетучих } \\
\text { примесей }\end{array}$ & $\begin{array}{c}\text { Для предотвращения помех в работе детектора } \\
\text { и колонок }\end{array}$ & 5 \\
\hline Стоимость & Невысокая & Для снижения расходов на анализ & 3 \\
\hline $\begin{array}{l}\text { Совместимость с во- } \\
\text { дой (буфером) }\end{array}$ & Высокая & $\begin{array}{l}\text { Для избегания расслоения элюента, выпадения } \\
\text { буфера в осадок и помех при детектировании }\end{array}$ & $5(4)$ \\
\hline Элюирующая сила & $\begin{array}{l}\text { Достаточно } \\
\text { большая }\end{array}$ & Для сокращения времени анализа & 4 \\
\hline $\begin{array}{c}\text { Солюбилизирующая } \\
\text { способность }\end{array}$ & Высокая & $\begin{array}{c}\text { Для предотвращения выпадения осадка аналита } \\
\text { в хроматографическом тракте }\end{array}$ & 4 \\
\hline Токсичность & Низкая & Для обеспечения безопасности работ & 3 \\
\hline Воспламеняемость & Низкая & $\begin{array}{c}\text { Для обеспечения безопасности при хранении и } \\
\text { использовании }\end{array}$ & 3 \\
\hline
\end{tabular}


Эти растворители демонстрируют ряд превосходных свойств, но в целом по сумме технических параметров уступают ацетонитрилу, именно поэтому $\mathrm{MeCN}$ и его смеси с водой и буферными растворами являются самыми востребованными в качестве гидрофильных экстрагентов и компонентов подвижных фаз в экстракционно-хроматографических способах аналитического контроля широкого спектра органических веществ [2-6,14].

Таблица 2. Физические свойства растворителей для ОФ ВЭ ЖХ. По данным [3]

\begin{tabular}{|c|c|c|c|c|c|}
\hline Растворители & $\mathrm{T}_{\text {кип, }}{ }^{\circ} \mathrm{C}$ & $\begin{array}{c}\rho \text { при } 298 \mathrm{~K}, \\
\Gamma / \mathrm{cm}^{3}\end{array}$ & $n_{D}^{25}$ & $\begin{array}{c}\eta \cdot 10^{3},(\Pi a \times c) \\
298 \mathrm{~K}\end{array}$ & $\begin{array}{c}\text { Порог про- } \\
\text { зрачности } \\
\text { УФ, нм }\end{array}$ \\
\hline $\mathrm{MeCN}$ & 81.6 & 0.7767 & 1.3416 & 0.341 & 195 \\
\hline Вода & 100.0 & 0.9971 & 1.3325 & 0.894 & 190 \\
\hline 1,4-Диоксан & 101.3 & 1.0268 & 1.4203 & 1.194 & 225 \\
\hline Метанол & 64.5 & 0.7868 & 1.3265 & 0.545 & 205 \\
\hline ИПС & 82.4 & 0.7810 & 1.3752 & 2.073 & 205 \\
\hline ТГФ & 66.0 & 0.8842 & 1.4036 & 0.460 & 212 \\
\hline
\end{tabular}

Таблица 3. Технические свойства растворителей для ОФ ВЭЖХ [3]

\begin{tabular}{|c|c|c|c|c|c|c|}
\hline \multirow[t]{2}{*}{ Растворители } & \multirow[t]{2}{*}{$\begin{array}{c}\text { Относительная } \\
\text { стоимость }\end{array}$} & \multirow[t]{2}{*}{$\begin{array}{l}\text { ПДК, } \\
\mathrm{мг} / \mathrm{m}^{3}\end{array}$} & \multirow[t]{2}{*}{$T_{\text {всп }},{ }^{\circ} \mathrm{C}$} & \multirow[t]{2}{*}{$T_{\text {самов }},{ }^{\circ} \mathrm{C}$} & \multicolumn{2}{|c|}{$\begin{array}{c}\text { Концентрационные } \\
\text { пределы воспламене- } \\
\text { ния, \% об. }\end{array}$} \\
\hline & & & & & нижний & верхний \\
\hline $\mathrm{MeCN}$ & 1.84 & 10 & 6 & 523 & 4 & 16 \\
\hline 1,4-Диоксан & 2.16 & 10 & 5 & 300 & 2.0 & 22.5 \\
\hline Метанол & 1.00 & 5 & 11 & 464 & 7.3 & 36 \\
\hline ИПС & 1.14 & 980 & 11.7 & 400 & 2.23 & 12.7 \\
\hline ТГФ & 2.37 & 100 & -20 & 250 & 1.8 & 11.8 \\
\hline
\end{tabular}

Таблица 4. Параметры полярности и элюирующей способности растворителей для ОФ ВЭЖХ. По данным [2-5]

\begin{tabular}{|c|c|c|c|c|c|c|c|c|}
\hline Растворители & $\varepsilon_{r}$ & $\mu, \mathrm{D}$ & $\begin{array}{c}\delta_{\mathrm{T}}, \\
\mathrm{M \Pi a}^{1 / 2} \\
\end{array}$ & $\begin{array}{c}E_{T}(30), \\
\text { кДж/моль }\end{array}$ & $P^{\prime}$ & $\varepsilon^{\circ}\left(\mathrm{SiO}_{2}\right)$ & $\varepsilon^{\circ}\left(\mathrm{C}_{18}\right)$ & $S$ \\
\hline $\mathrm{MeCN}$ & 35.94 & 3.44 & 26.90 & 190.8 & 5.8 & 0.60 & 3.1 & 3.1 \\
\hline Вода & 78.54 & 1.83 & 52.20 & 264.0 & 10.2 & - & - & 0 \\
\hline 1,4-диоксан & 2.21 & 0.45 & 21.78 & 150.6 & 4.8 & 0.60 & 11.7 & 3.5 \\
\hline Метанол & 32.66 & 1.70 & 32.42 & 231.8 & 5.1 & 0.70 & 1.0 & 3.0 \\
\hline ИПС & 19.13 & 1.66 & 25.30 & 202.5 & 3.9 & 0.55 & 8.3 & 4.2 \\
\hline ТГФ & 7.39 & 1.75 & 20.21 & 156.5 & 4.0 & 0.44 & 3.7 & 4.4 \\
\hline
\end{tabular}

Природа не изобрела идеального растворителя, поэтому в аналитической ВЭЖХ и ЖЖЭ нашли применение смеси растворителей. Индивидуальный МеCN практически не применяется в качестве элюента или экстрагента. В ОФ ВЭЖХ, он, как известно, является модификатором подвижной фазы, а вода - разбавителем. Объемная доля $\mathrm{MeCN}$ в элюентах может варьировать в самом широком диапазоне, от нескольких объемных процентов до 90-95\%. Рассмотрим, как изменяются главные хроматографические свойства смесей $\mathrm{MeCN}$ - вода от объемной доли последнего $\left(\varphi_{2}\right)$ во всем диапазоне изменений его концентрации от 0 до 1 (0-100\% об.).

Плотность. В [16,17] показано, что для бинарных смесей растворителей изотермы плотности $\rho_{12}=f\left(\varphi_{2}\right)$ адекватно описываются биномиальным уравнением:

$$
\rho_{12}=\rho_{1}+\beta \rho_{1} \varphi_{2}+\left(\rho_{2}-\beta \rho_{1}-\rho_{1}\right) \varphi_{2}^{2}
$$


где $\beta$ - эмпирический коэффициент; $\rho_{1}$ и $\rho_{2}-$ показатели плотности разбавителя и модификатора, соответственно; $\varphi_{2}$ - объемная доля модификатора. Граничное условие уравнения (1): при $\varphi_{2}=0$ или 1 значения $\rho$ равны плотности исходных смешиваемых растворителей.

Найдено, что при $25^{\circ} \mathrm{C}$ для смеси $\mathrm{MeCN}-$ вода $\beta=-0.22$. Как видно из 3Dдиаграммы (рис.1), для зависимости $\rho_{12}=f\left(\varphi_{2}\right)$ характерна слабо выраженная нелинейность (неаддитивность) от состава. С увеличением температуры плотность монотонно уменьшается. В интервале температур 277-298 К (4-25 $\left.{ }^{\circ} \mathrm{C}\right)$ это изменение можно описать линейным уравнением (табл. 5):

$$
\rho_{i}=a-b T_{i}
$$

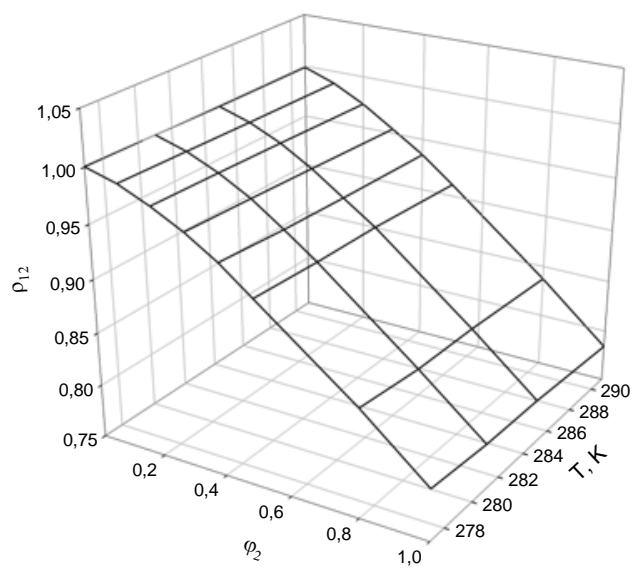

Рис. 1. Зависимость плотности смесей $\mathrm{MeCN}$ - вода от состава и температуры [17]

Таблица 5. Коэффициенты уравнения (2) для разных составов смесей $\mathrm{MeCN}$ - вода [16]

\begin{tabular}{|c|c|c|}
\hline$\varphi_{2}$ & $a$ & $b \times 10^{3}$ \\
\hline 0 & 1.03 & 0.1 \\
\hline 0.1 & 1.04 & 0.2 \\
\hline 0.2 & 1.04 & 0.3 \\
\hline 0.3 & 1.05 & 0.4 \\
\hline 0.4 & 1.05 & 0.5 \\
\hline 0.5 & 1.05 & 0.6 \\
\hline 0.8 & 1.07 & 0.8 \\
\hline 1 & 1.07 & 1.0 \\
\hline
\end{tabular}

При повышении температуры плотность водно-ацетонитрильных смесей уменьшается немного сильнее, чем у чистой воды. Этот эффект обусловлен тем, что равновесие между гомо- и гетеромежмолекулярными ассоциатами при увеличении температуры смещается в сторону более «рыхлых» структур. Надо отметить, что этот эффект сильнее выражен для смесей, в которых вода образует водородные связи с модификатором (спирты, ТГФ, диоксан)[16,17].

Вязкость. Динамический коэффициент вязкости $\eta$ - ключевая физикохимическая величина, характеризующая свойство жидкостей оказывать сопротивление перемещению одного ее слоя относительно другого. Противодавление, возникающее в хроматографической системе (в первую очередь в колонке), зависит от вязкости элюента, извилистости пути потока по хроматографическому тракту (по колонке, капиллярным трубкам, ячейке детектора) и от скорости потока. При одинаковой скорости элюирования менее вязкие элюенты требуют меньшего входного 
давления. Однако вязкость влияет не только на механическую работу хроматографа, но и на эффективность хроматографической системы в целом. Чем ниже вязкость элюента, тем эффективней массообмен, выше скорость диффузии и, в конечном счете, меньше размывание хроматографических пиков [4,5].

Известно, что вязкость смешанных растворителей зависит от состава не линейно. Это вызывает проблемы при градиентном варианте ВЭЖХ. Вязкость обращенно-фазовых элюентов нередко выше вязкости чистых компонентов. Так, вязкость смеси метанол - вода в области эквиобъемных составов примерно в 1.8 раза больше вязкости воды, а вязкость смеси 1-пропанол - вода, взятых в этих же пропорциях, имеет вязкость в 2.5 раза больше вязкости чистой воды $[4,5]$.

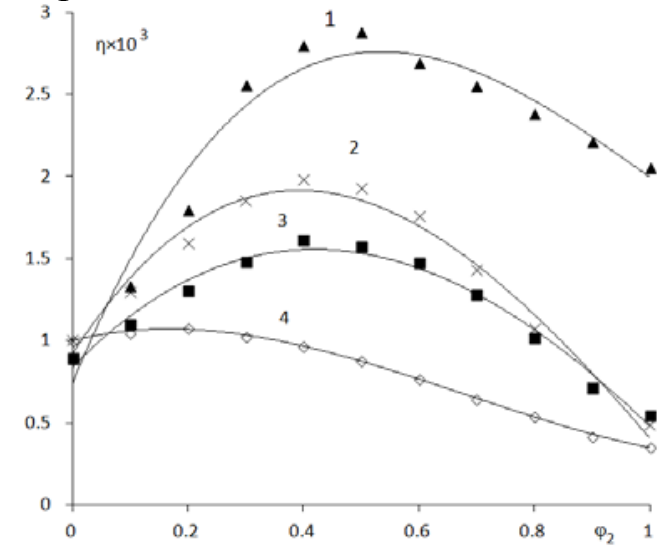

Рис. 2. Зависимость вязкости $($ Па $\times$ c) от состава для систем вода - растворитель: 1) ИПС, $25^{\circ} \mathrm{C}$; 2) ТГФ, $20^{\circ} \mathrm{C}$; 3 ) метанол, $25^{\circ} \mathrm{C}$; и 4) $\mathrm{MeCN}, 20^{\circ} \mathrm{C}$. По данным [17].

В результате сильного роста вязкости при создании градиента 0-100\% в системе спирт - вода противодавление возрастает в 2-3 раза, что негативно влияет на работу насосов хроматографа и предъявляет к ним повышенные требования. Разницу в характере зависимостей $\eta_{12}=f\left(\varphi_{2}\right)$ у водно-ацетонитрильных смесей и смесей воды с другими модификаторами наглядно демонстрирует рис. 2, из которого видно, что ацетонитрил имеет уникальные преимущества перед другими растворителями. Максимальная вязкость его смеси с водой в диапазоне $\varphi_{2}=0.1-0.2$ только на 3\% больше вязкости чистой воды.

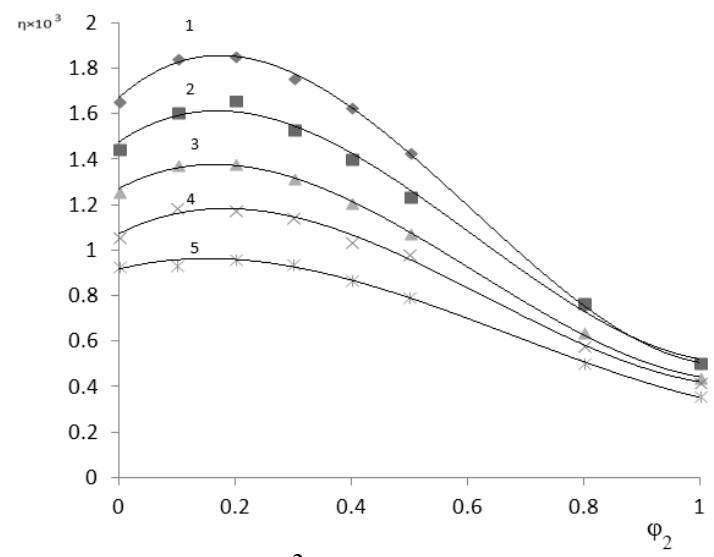

Рис. 3. Вязкость $\left(\eta \times 10^{3}\right.$, Пахс) системы МеСN - вода при разных температурах, $1-3 ; 2-8 ; 3-13 ; 4-18 ; 5-23^{\circ} \mathrm{C}$. По данным [19].

Для аппроксимации зависимостей $\eta_{12}=f\left(\varphi_{2}\right)$ биномиальные уравнения типа (1) оказались непригодными, в [18] предложено рациональное уравнение (3), которое с высокой степенью аппроксимации описывает экспериментальные данные. 


$$
\eta_{12}=\left\{\eta_{1}+\left[\eta_{2}(1+A+B)-\eta_{1}\right] \varphi_{2}\right\} /\left(1+A \varphi_{2}+B \varphi_{2}^{2}\right),
$$

где $\eta_{12}$ - коэффициент динамической вязкости смеси, а $\eta_{1}$ и $\eta_{2}-$ вязкости чистого разбавителя и исходного модификатора, $A$ и $B$ - эмпирические коэффициенты, характеризующие взаимодействие компонентов смеси. Для ацетонитрила $\mathrm{A}=-1.05$, $\mathrm{B}=1.45\left(20^{\circ} \mathrm{C}\right)$.

При нагреве на 10 градусов вязкость индивидуальных и смешанных растворителей уменьшается на 4-20\% (рис.3). Отрицательный эффект на работу хроматографической системы от повышения вязкости при необходимости можно нивелировать термостатированием при сравнительно невысоких температурах (40-75 $\mathrm{C})$.

Коэффициент проницаемости. В работе [19] изучали коэффициент проницаемости $\psi$ бинарных смесей. Он равен отношению коэффициента поверхностного натяжения к коэффициенту динамической вязкости ( $\psi=\sigma / \eta$, размерность $M / c)$. Найдено, что $\psi_{12}$ для бинарных систем вода - органический растворитель адекватно аппроксимируется модифицированным полиномом 3-й степени:

$$
\psi_{12}=\psi_{1}+A \psi_{1} \varphi_{2}+\left(B \psi_{2}-A \psi_{1}-\psi_{1}\right) \varphi_{2}^{2}+\left(\psi_{2}-B \psi_{2}\right) \varphi_{2}^{3},
$$

где для $\mathrm{MeCN}$ эмпирические коэффициенты $A=-3.09, B=2.58$. На (рис. 4) представлены полученные изотермы $\psi_{12}=f\left(\varphi_{2}\right)$.

Коэффициент $\psi$ характеризует постоянную потока жидкости через капилляр $\chi$ и позволяет прогнозировать расстояния, проходимые фронтом конкретного растворителя за определенное время в ТСХ в пористом слое сорбента:

$$
\chi=2 k_{0} d_{p} \psi
$$

где $k_{0}$ - параметр проницаемости, зависящий от структуры внешних пор, $d_{p}-$ диаметр частиц сорбента.

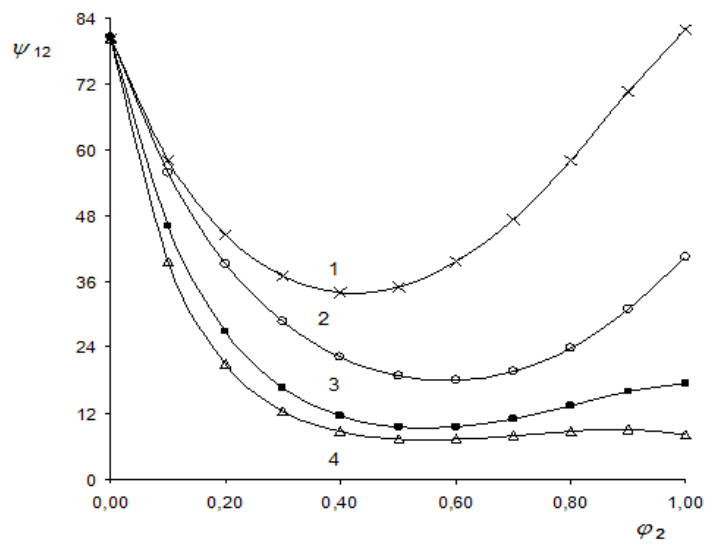

Рис. 4. Изотермы проницаемости $\Psi_{12}(\mathrm{M} / \mathrm{c})$ бинарных систем вода - модификатор от объемной доли модификатора $\varphi_{2}: 1$ - $\mathrm{MeCN} ; 2$ - метанол; 3 - этанол; 4 - ИПС. По данным [19].

Величина коэффициента $\psi$ чистого $\mathrm{MeCN}$ выше, чем у спиртов, т.е. при прочих равных условиях постоянная потока МeCN выше, чем у спиртов и сопоставима с величиной коэффициента проницаемости воды, для эквиобъемных составов $\mathrm{MeCN}$ - вода наблюдается минимум (рис. 4). Водно-спиртовые составы с $\varphi_{2}=0.40-80$ в условиях ОФ ТСХ имеют слишком низкую проницаемость, для этого варианта хроматографии предпочтительнее по параметру $\psi$ являются водноацетонитрильные подвижные фазы.

Показатель преломления. Вместе с ВЭЖХ широко применяют рефрактометрические детекторы (РМД). Они являются неспецифическими (универсальными) детекторами [1-5]. Чувствительность РМД определяется разностью показателей преломления элюента и сорбата $\Delta n$. Для многих бинарных 
систем растворителей биномиальные функции (6), аналогичные найденным для плотности, хорошо описывают эксперимент [21].

$$
n_{12}=n_{1}+\alpha n_{1} \varphi_{2}+\left(n_{2}-\alpha n_{1}-n_{1}\right) \varphi_{2}^{2} \text {, }
$$

где $\alpha$ - эмпирический коэффициент. На рис. 5 приведены кривые $n_{12}=f\left(\varphi_{2}\right)$, построенные для некоторых типичных бинарных водно-органических смесей. Уравнение (6) адекватно аппроксимирует изотермы $n_{12}=f\left(\varphi_{2}\right)$ (в большинстве случаев коэффициент корреляции $R>0.99)$. Справедливости ради отметим, что для системы метанол - вода наряду с бинарным полиномом (6), имеющим относительно низкий коэффициент парной корреляции $R \approx 0.92$, более подходит модифицированный полином 3-й степени (7), имеющий такие же граничные условия, как и все описанные выше уравнения, а именно при $\varphi_{2}=0$ или 1 значения $n$ равны $n_{1}$ и $n_{2}$ соответственно $(R=0.998)$.

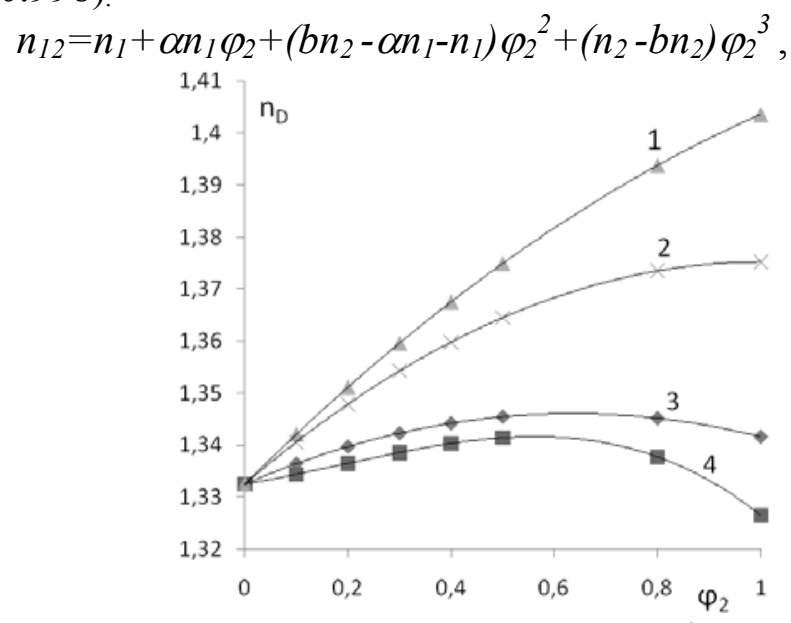

Рис. 5. Изотермы показателя преломления для бинарных систем вода модификатор, $20{ }^{\circ} \mathrm{C}: 1$ - ТГФ; 2 - ИПС; 3 - $\mathrm{MeCN} ; 4$ - метанол. По данным [21].

Очевидно, что водные смеси с $\mathrm{MeCN}$ и метанолом имеют преимущество при использовании РМД. Следует учитывать, что с повышением температуры показатель преломления уменьшается (рис. 6).

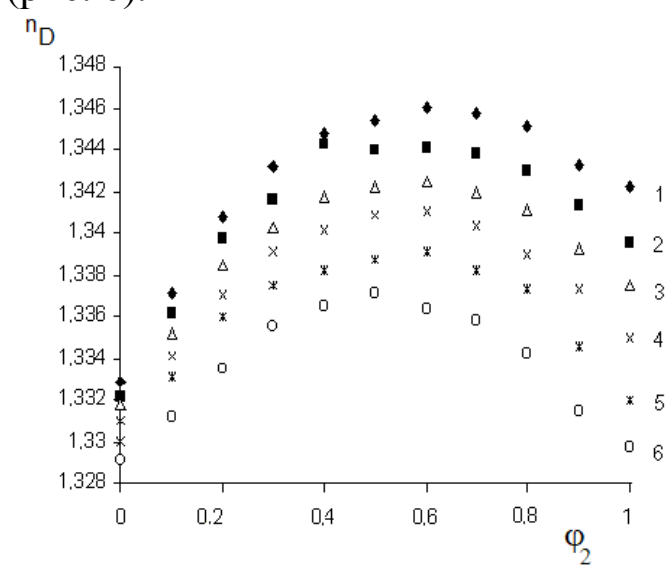

Рис. 6. Влияние температуры на показатель преломления для смесей $\mathrm{MeCN}-$ вода: 1 - 298 К; 2 - 303 К; 3 -308 К; 4 - 313 К; 5 - 318 К; 6 - 323 К. По данным [22].

Оптическая плотность. Смеси МеCN - вода имеют высокую прозрачность в широком диапазоне длин волн (рис. 7) [2-54], что позволяет использовать ультрафиолетовый детектор при проведении спектрофотометрического анализа или анализа методом ВЭЖХ-УФ для регистрации аналитических сигналов органических соединений, имеющих максимумы поглощения в коротковолновом диапазоне УФспектра (205-220 нм). Главное условие, чтобы в МеCN отсутствовали характерные 
для него примеси акрилонитрила и других ненасыщенных соединений с сопряженными кратными связями, т.е. $\mathrm{MeCN}$ должен иметь квалификацию «чистый для спектроскопии», «особо чистый для ВЭЖХ». В работе [23] показано, что для бинарных водно-органических смесей можно применять уравнение (8), если считать воду прозрачной при аналитических длинах волн $>195$ нм:

$$
A_{12}=\left(A_{2}-\beta\right) \varphi_{2}+\beta_{12} \varphi_{2}^{2} .
$$

где $A_{12}$ - оптическая плотность бинарного раствора, $A_{2}$ - оптическая плотность органического модификатора, $\beta$ - эмпирический коэффициент, характеризующий бинарную систему.

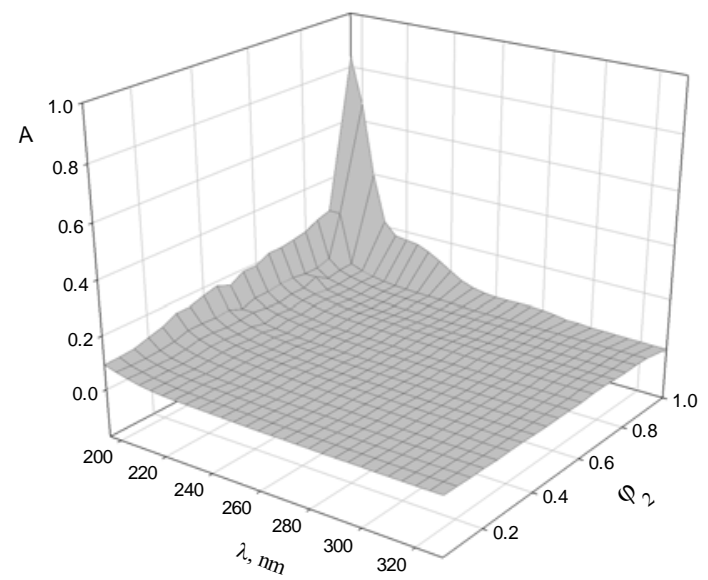

Рис. 7. Поглощение смесей $\mathrm{MeCN}$ - вода при разных длинах волн. Спектрофотометр Шимадзу UV-1800 [24].

В работе [24] изучено отклонение оптической плотности смесей ацетонитрила с водой $A_{12}$ от аддитивности. Показано, что зависимость $A_{12}=f\left(\varphi_{2}\right)$ принципиально различна в диапазонах 195-235 нм и при $\lambda>240$ нм. В первом диапазоне наблюдается резкая нелинейность при больших концентрациях $\mathrm{MeCN}$, а во втором - нелинейность сравнима по порядку величины с флюктуациями оптической плотности. Не исключено, что в смесях с максимально высоким содержанием MeCN могут при комнатных температурах наблюдаться стохастические нарушения гомогенности системы на наноуровне, которые при охлаждении до отрицательных температур служат зародышами образования новой жидкой фазы. Склонность ацетонитрила к образованию гетерогенных фаз с водой особо явно проявляется при пониженных температуpax, о чем речь пойдет ниже.

Наличие наноразмерных гетероструктур должно привести к тому, что наряду с поглощением излучения имеет место его рассеяние. Наличие рассеяния требует дополнительного изучения. Химическая природа $\mathrm{MeCN}$ существенно отличается от химической природы спиртов и воды. Он имеет достаточно высокую полярность, сопоставимую с полярностью метанола, но, как апротонный растворитель $\mathrm{MeCN}$ не образует водородных связей с водой, являясь лишь слабым акцептором водородной связи. Структуры бинарных смесей МeCN с водой до сих пор представляют научный интерес, но остаются неразрешенными [12]. Структуры сольватов $\mathrm{MeCN}$ и метанола в смесях с водой существенно различаются. В частности, установлено, что смесь $\mathrm{MeCN}$ - вода следует рассматривать, по крайней мере, как трехкомпонентную систему, в которой в растворе могут существовать две различные формы $\mathrm{MeCN}$ [25]. Одновременное существование сильных водородных связей между молекулами воды и слабополярных самоассоциированных форм МеCN специфически влияет на физические и химические свойства смесей $\mathrm{MeCN}$ - вода. 
Температура кипения. Знание температуры кипения растворителей имеет значение не только для контроля режима работы хроматографа в условиях термостатирования колонки, но и для контроля концентрирования экстракта при упаривании экстрагента, при оценке пожаровзрывоопасности в аналитической лаборатории [3]. Для прогноза температуры кипения бинарной системы $\mathrm{MeCN}$ - вода произвольного состава в работе [26] предложено использовать рациональную функцию (9), проходящую через три важнейшие экспериментальные точки $T_{1}, T_{2}$ и $T_{A}$,

$$
T_{12}=\frac{T_{1}+\left[T_{2}(1+A+B)-T_{1}\right] \varphi_{2}}{1+A \varphi_{2}+B \varphi_{2}^{2}}
$$

где $T_{12}-$ температура кипения бинарной смеси, а $T_{1}$ и $T_{2}-T_{\text {кип }}$ воды и $\mathrm{MeCN}$ (100 и $\left.81.6^{\circ} \mathrm{C}\right), T_{A}$ - температура кипения азеотропного состава $\left(77.0^{\circ} \mathrm{C}\right), A=-0.521, B=-0.386$.

На Рис. 8 приведена зависимость температуры кипения смеси $\mathrm{MeCN}$ - вода от состава, минимум которой приходится на азеотропную смесь.

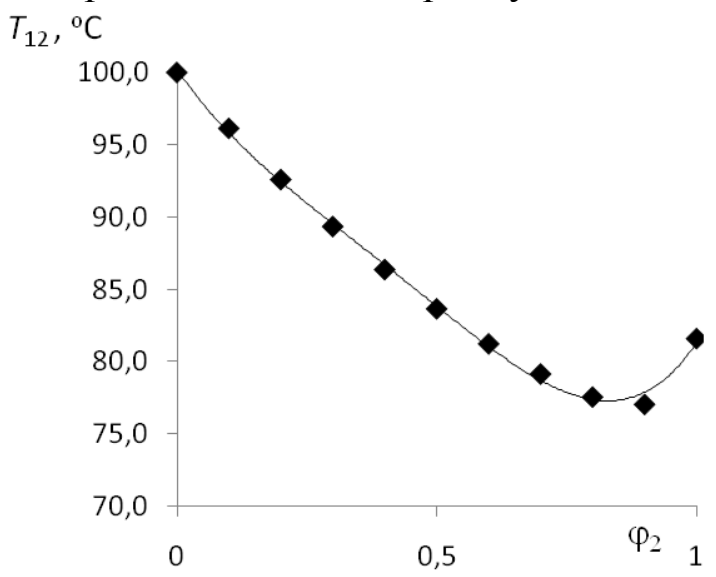

Рис. 9. Зависимость температуры кипения смеси $\mathrm{MeCN}$ - вода от объемной доли $\mathrm{MeCN}$

Азеотропные смеси легко регенерируются перегонкой и могут использоваться в рецикле. Это важно для лабораторий с низким бюджетом.

Температура замерзания. Данные по температуре замерзания ацетонитрила и его водных растворов в разных источниках отличаются [12]. Приводится разброс значений от -46 до $-41{ }^{\circ} \mathrm{C}$. Увы, практически все результаты определения физикохимических параметров индивидуальных, а тем более смешанных растворителей, имеют по мнению известного ученого Ревельского И.А. всегда определенную ошибку, так как при их нахождении трудно учесть наличие не обнаруженных или неизвестных примесей. В любом органическом растворителе есть следы примесей, состав которых зависит от способа получения. Все органические растворители, если их специально не подвергают абсолютированию, содержат следы влаги $(\varphi=0.0001$ 0.0025). В работе [12] обсужден сложный и нелинейный профиль кривых температуры замерзания смесей МeCN с водой. Отмечено, что начиная с $\varphi=0.90 \mathrm{MeCN}$ в воде, температура замерзания быстро уменьшается. Минимальная температура замерзания $\left(-44.9^{\circ} \mathrm{C}\right)$ характерна для смеси, содержащей $\mathrm{MeCN}$ в количестве $\varphi=0.98$ (98 \% об.). Точку замерзания чистого $\mathrm{MeCN}$ авторы работы [12] указывают при $-43.4^{\circ} \mathrm{C}$. Таким образом, температура замерзания $\mathrm{MeCN}$ может заметно изменяться в зависимости от присутствия следов воды и других минорных примесей. Нетипичный характер замерзания смесей МeCN с водой может быть связан с изменением полярности бинарного растворителя в диапазоне концентраций $\mathrm{MeCN} \varphi=0.90-1$. Это важный вывод для его прикладного использования в ОФ ВЭЖХ. В работе [12] отмечено хромато- 
графическое поведение стероидов в этом узком диапазоне составов бинарных смесей $\mathrm{MeCN}$ с водой, характерное для условий нормально-фазовой ВЭЖХ, где подвижная фаза менее полярна, чем неподвижная. Это наблюдение непосредственно подтверждает, что полярность подвижной фазы, состоящей в основном из $\mathrm{MeCN}$, значительно изменяется, когда его концентрация приближается к 100\%. Отсюда можно сделать вывод, что чистый МeCN с низким содержанием воды может функционировать как относительно неполярный сольвент, однако его полярность легко изменяется путем добавления небольшого объема воды.

Полярность и элюирующая сила. Под полярностью растворителей понимается их способность сольватировать находящиеся в нем заряженные или полярные частицы. Эта способность зависит от всех специфических и неспецифических взаимодействий между молекулами растворителя и растворенного вещества. Учесть в полной мере совокупность всех этих взаимодействий каким-то одним физикохимическим параметром невозможно. В связи с этим количественно полярность растворителей чаще всего определяют с помощью различных эмпирических параметров.

В табл. 4 приведены данные о диэлектрической проницаемости $\varepsilon_{r}$, дипольном моменте $\mu$, параметре растворимости Гильдебранда $\delta_{T}$, сольватохромном параметре Димрота-Райхардта $\mathrm{E}_{\mathrm{T}}(30)$, полярности Снайдера $P^{\prime}$ для $\mathrm{MeCN}$ и других растворителей для ОФ ВЭЖХ. Эти показатели являются частными критериями полярности растворителей. Недостатки и специфика этих критериев полярности детально обсуждены в [2-4, 27,28]. Упомянутые критерии устанавливают похожие в большей или меньшей степени порядки изменения полярности растворителей, т.е. между разными шкалами полярности прослеживаются приближенные корреляции. Вместе с тем, в отдельных случаях некритичное использование конкретного критерия может приводить к промахам в оценке хроматографических и экстракционных свойств растворителей, так как ни один их них не учитывает в полной мере всего комплекса взаимодействий и явлений, сопутствующих хроматографическим, сорбционным и экстракционным процессам. В связи с этим в работе [28] предложено использовать обобщенный (редуктивный) критерий полярности $P_{\mathrm{N}}$. Он получен путем обобщения параметров $P^{\prime}, \delta_{T}, \varepsilon_{r}$ и $E_{T}(30)$ растворителей, для которых известны все 4 обобщаемых параметра. Величины $P_{\mathrm{N}}$ нормализованы таким образом, что максимальное значение критерия полярности для воды равно 100, а минимальное значение $P_{\mathrm{N}}$ для декана приравнено нулю. Термин редуктивный подчеркивает основной смысл критерия - сокращение (редукция) числа переменных, используемых в оценке полярности. Весовые коэффициенты парциальных полярностей приняты одинаковыми. Хотя был предложен алгоритм их оптимизации для оценки элюирующей способности растворителей на разных сорбентах по экспериментальным значениям элюирующей силы на конкретных сорбентах. Однако в настоящее время многочисленные сорбенты нового поколения радикально отличаются по характеристикам от сорбентов, которые были синтезированы 40-50 лет назад и «подгонять» под каждый новый сорбент критерий полярности не целесообразно. Как видно из табл. 6 полярность ацетонитрила $P_{\mathrm{N}}=44.66$ действительно близка к среднему значению.

Элюирующая сила растворителей определяется в первую очередь их полярностью. В условиях нормально-фазовой ВЭЖХ элюирующая сила возрастает с увеличением полярности подвижной фазы, а в условиях ОФ ВЭЖХ, наоборот, чем выше полярность подвижной фазы, тем меньше ее элюирующая способность. 
Таблица 6. Обобщенные критерии полярности $P_{N}$ и липофильности $R_{L}$ некоторых растворителей для жидкостной хроматографии. По данным [28,29]

\begin{tabular}{|c|c|c|c|c|c|}
\hline Растворитель & $P_{N}$ & $R_{L}$ & Растворитель & $P_{N}$ & $R_{L}$ \\
\hline Декан & 0.00 & 100 & Ацетон & 32.18 & 67.82 \\
\hline Изооктан & 0.32 & 99.68 & Бутанол-1 & 36.29 & 63.71 \\
\hline Гексан & 0.85 & 99.15 & ИПС & 36.72 & 63.28 \\
\hline Гептан & 1.44 & 98.56 & Уксусная кислота & 38.45 & 61.55 \\
\hline Диизопропиловый эфир & 9.02 & 90.98 & Пропанол-1 & 39.09 & 60.91 \\
\hline Диэтиловый эфир & 11.73 & 88.27 & ДМФА & 42.88 & 57.12 \\
\hline ТГФ & 21.00 & 79.00 & Этанол & 43.97 & 56.03 \\
\hline 1,4-Диоксан & 21.71 & 78.29 & Ацетонитрил & 44.66 & 55.34 \\
\hline Этилацетат & 21.84 & 78.16 & ДМСО & 48.41 & 51.59 \\
\hline Хлороформ & 22.00 & 78 & Метанол & 54.34 & 45.66 \\
\hline Метиленхлорид & 23.04 & 76.96 & Вода & 100.00 & 0 \\
\hline
\end{tabular}

Фактор удерживания в условиях ОФ ВЭЖХ в общем случае нелинейно зависит от состава элюента, эту зависимость можно выразить биномиальным уравнениeм:

$$
\ln k=A \varphi_{2}^{2}+B \varphi_{2}+C,
$$

где $A, B$ и $C$ - эмпирические коэффициенты; $A$ имеет положительный знак, $B-$ большую величину и отрицательный знак, $C$ - натуральный логарифм $k$ в чистой воде. Справедливость уравнения (10) подтверждена на многочисленных экспериментальных данных [2]. Значительные отклонения от этой зависимости могут наблюдаться при низком содержании модификатора $\left(\varphi_{2}<0.1\right)$. Коэффициент $C$ не обязательно соответствует фактору удерживания в чистой воде. В [2] рассмотрены и другие способы математического описания зависимостей фактора удерживания от $\varphi_{2}$ в условиях ОФ ВЭЖХ. Использование нелинейных зависимостей облегчает описание влияния состава на удерживание в широком диапазоне $\varphi_{2}$. В узких интервалах $\varphi_{2}$ фактор удерживания $k=1-10$ и адекватно описывается линейным уравнением (11).

$$
\lg k=\lg k_{1}-S \varphi_{2},
$$

где $k_{1}$ - фактор удерживания при использовании воды в качестве подвижной фазы; $\varphi_{2}-$ объемная доля органического модификатора. Коэффициент $S$ является одной из мер элюирующей силы в ОФ ВЭЖХ (табл. 4). Недостатком критерия $S$ является тот факт, что он не является постоянной величиной для той или иной неподвижной фазы и двух компонентов выбранного элюента и зависит от фактора удерживания сорбата, кроме того, уравнение (11) приблизительно соблюдается лишь при изменении состава элюента в пределах $30 \%$ [2]. Коэффициент $k_{1}$, как и $C$, в уравнении (10) не дает точной оценки удерживания в воде. Для тройных систем уравнение (10) пригодно только в том случае, если используются псевдобинарные системы, т.е. тройные смеси, в которых соотношение объемных долей двух модификаторов постоянны.

Для расчета изоэлюотропных составов (т.е. составов с равной элюирующей силой) в ОФ ВЭЖХ применяли аддитивные схемы как для диэлектрической проницаемости $\varepsilon_{r}$, полярности $P^{\prime}$, растворимости Гильдебранда $\delta_{T}$, сольватохромного параметра $E_{T}^{N}[2-4,27]$, так и для обобщенных критериев полярности, являющихся комбинацией предыдущих 4-х показателей $[28,29]$. Действительно, зависимость $\varepsilon_{r}$ и $P$ 'от состава в водных смесях $\mathrm{MeCN}$ и метанола близка к линейной. Если отбросить относительно быстрое изменение $E_{T}{ }^{\mathrm{N}}$ для смесей воды с большинством модификаторов в области $\varphi_{2}=0.95-1.0$, а для $\mathrm{MeCN}$ еще и в области $\varphi_{2}=0-0.05$, которые обусловлены спецификой сольватохромного эффекта, параметр $E_{T}^{N}$ также адекватно описы- 
вается линейной зависимостью от объемной доли воды. Если допущение об аддитивности принято для частных критериев полярности, логично распространить его и на обобщенный критерий $P_{N}$, образованный на их основе. В первом приближении можно считать, что в смесях одинаковой полярности примерно одинаковыми будут и параметры удерживания сорбата [28,29]. По нашему мнению весьма привлекательным для определения элюирующей силы элюента в условиях ОФ ВЭЖХ является критерий $R_{L}=100-\mathrm{P}_{\mathrm{N}}$. Критерий $R_{L}$ назвали редуктивным липофильным [29]. В отличие от критерия полярности, он характеризует липофильные свойства растворителей. Как видно из Табл. $6, \mathrm{MeCN}$ тяготеет к середине значений от 0 до 100 как по параметру $P_{N}$, так и по параметру $R_{L}$, т.е. имеет хороший баланс между полярностью и липофильностью.

Корреляция между коэффициентом $S$ и критерием $R_{L}$ в известном ряду растворителей имеет вид: $\mathrm{S}=0.056 R_{L}[29]$. Таким образом, элюирующая сила бинарной системы вода - модификатор будет определяться простым линейным выражением, удобным в хроматографической практике:

$$
R_{L}=R_{L 2} \varphi^{2}
$$

где $R_{L 2}$ - элюирующая сила модификатора, а $\varphi_{2}$ - его объемная доля. Критерий $R_{L}$ предпочтительней для характеристики элюирующей силы в ОФ ВЭЖХ, чем критерий $P_{N}$, так как мы имеем дело с прямой зависимостью, а в расчетах исчезает параметр воды. Конечно, критерий $R_{L}$ не учитывает влияния $\mathrm{pH}$ среды, если вместо воды применяют буферные растворы. Величина $\mathrm{pH}$ влияет на параметры удерживания ионогенных веществ (слабых кислот и оснований) и практически не влияет на удерживание неионогенных аналитов [2].

Зависимости физико-химических свойств смесей ацетонитрила с водой от их состава использованы в подборе оптимизированных с применением обобщенных целевых функций методик определения БАВ с применением ВЭЖХ [3,4,14].

\section{Экстракционные свойства ацетонитрила и его смесей с водой}

Свойства, представленные в табл. 1, можно смело отнести не только к хроматографическим, но также и к экстракционным свойствам. Ибо экстрагируемые аналиты, перераспределяясь в процессе экстракции из твердой или водной матрицы в органический экстрагент в ходе подготовки пробы, далее идут на хроматографический анализ. Растворитель пробы (экстракта) по возможности должен быть максимально совместим с элюентом, хорошо смешиваться с ним, не мешать детектированию своим поглощением, не влиять существенно на элюирующую силу и т.д. [4]. В идеале состав экстрагента должен совпадать с составом элюента. В связи с этим $\mathrm{MeCN}$ представляет большой интерес как компонент экстракционной системы.

$\mathrm{B}$ настоящее время $\mathrm{MeCN}$ получил широкое применение в качестве гидрофильного экстрагента как сам по себе, так и в составе смешанных экстрагентов в самых разнообразных методах экстракции: твердофазной экстракции (ТФЭ); микроТФЭ; низкотемпературной ТФЭ; ЖЖЭ с высаливанием и высахариванием; микроЖЖЭ; дисперсионной микро-ЖЖЭ, жидкостной экстракции под давлением; флюидной экстракции, низкотемпературной ЖЖЭ, экстракционном вымораживании; комбинированном методе квечерс (QuEChERS)[6-11,13,15,30-42].

Смешиваемость и солюбилизирующая способность. В методах ЖЖЭ важным свойством растворителей является их смешиваемость между собой. Если они не смешиваются, тогда один растворитель может служить экстрагентом аналита из другого растворителя. На практике важным свойством является смешиваемость с водой. По этому свойству растворители можно разделить на гидрофобные и гидрофильные. 
Известен эмпирический миксотропный ряд [3], сокращенная выборка из него приведена в Табл 7.

Растворители, расположенные в миксотропном ряду выше трет-бутанола, смешиваются с водой и между собой в любых соотношениях, их можно отнести к гидрофильным. Растворители ниже трет-бутанола являются гидрофобными и, как правило, хорошо смешиваются с неполярными растворителями типа бензола или гексана. Удобной количественной мерой для предварительного прогноза смешиваемости растворителей могут служить величины логарифма коэффициента распределения между водой и 1 -октанолом $(\log P$ или $C \log P)$. Последние взяты из справочной базы пакета программ CambridgeSoft ChemBioOffice Ultra 14.0 Suite $(C \log P$ - это $\log P$, найденный с помощью квантово-химических расчетов по алгоритму BioBite ${ }^{\circledR}$ ). Гидрофильные растворители с отрицательными или близкими к нулю критериями $(\log P \leq 0.6)$ полностью или частично смешиваются с водой и между собой, а растворители с положительными критериями гидрофобности неограниченно или частично смешиваются между собой и с гексаном. Чем больше разница в значениях критерия $\log P$ или $C \log P$, тем маловероятней совместимость. Есть и исключения, например, бензол хорошо смешивается с метанолом.

Таблица 7. Выборка из эмпирической миксотропной серии растворителей [3] и критерии гидрофобности $\log P$ и $C \log P$ в качестве меры смешиваемости

\begin{tabular}{|c|c|c|}
\hline Растворители & $\log P$ & ClogP \\
\hline Вода & - & -1.38 \\
\hline Ацетонитрил & 0.17 & -0.39 \\
\hline Метанол & -0.27 & -0.87 \\
\hline Этанол & 0.07 & -0.24 \\
\hline ИПС & 0.38 & 0.07 \\
\hline Ацетон & 0.20 & -0.21 \\
\hline Пропанол-1 & 0.55 & 0.29 \\
\hline 1,4-Диоксан & -0.31 & -0.39 \\
\hline Тетрагидрофуран & 0.40 & 0.53 \\
\hline трет-Бутанол & 0.60 & 0.47 \\
\hline 2-Бутанол & 0.87 & 0.60 \\
\hline Метилэтилкетон & 0.86 & 0.32 \\
\hline Циклогексанон & 1.43 & 0.87 \\
\hline 1-Бутанол & 0.97 & 0.82 \\
\hline Этилацетат & 0.29 & 0.71 \\
\hline Диэтиловый эфир & 0.76 & 0.87 \\
\hline Бутилацетат & 1.20 & 1.77 \\
\hline Диизопропиловый эфир & 1.40 & 1.49 \\
\hline Метиленхлорид & 1.01 & 1.25 \\
\hline Хлороформ & 1.67 & 1.95 \\
\hline Бензол & 2.03 & 2.14 \\
\hline Толуол & 2.52 & 2.64 \\
\hline Тетрахлорметан & 2.86 & 2.88 \\
\hline Циклогексан & 2.50 & 3.35 \\
\hline Гексан & 3.00 & 3.87 \\
\hline Гептан & 3.42 & 4.40 \\
\hline & & \\
\hline & & \\
\hline & & 0.96 \\
\hline
\end{tabular}

$\mathrm{MeCN}$, как ИПС, ТГФ и диоксан, можно отнести к универсальным растворителям, так как они смешиваются не только с водой и гидрофильными растворителями, но и с гидрофобными растворителями. 
Твердофазная экстракция. В результате осуществления сорбционных или ионообменных процессов становится возможным проведение концентрирования методом ТФЭ. Суть метода заключается в концентрировании анализируемых компонентов за счёт сорбции на твердом носителе (сорбенте или ионообменной смоле). ТФЭ получила широкое распространение, так как является удобным приемом при проведении массовых анализов. Для ТФЭ разработано большое и разнообразное количество патронов с сорбентами, реализующими различные типы взаимодействий между сорбентом и сорбатом [35].

Однако применение ТФЭ требует больших затрат, так как патроны или колонки с сорбентами достаточно дорогие, а расход жидкостей мало отличается от расхода при проведении традиционной ЖЖЭ. Ацетонитрил является одним из наиболее активно применяемых растворителей в ТФЭ [35].

Жидкостно-жидкостная экстракция. Физический механизм ЖЖЭ, по нашему мнению, близок механизму распределительной жидкостной хроматографии, в котором распределение сорбата происходит на границе жидкой подвижной фазы и слоя жидкой неподвижной фазы у поверхности сорбента. Самым доступным способом управления жидкостнохроматографическим процессом является варьирование состава подвижной фазы [1-5]. Аналогичный подход применим и к ЖЖЭ. Так, ЖЖЭ между несмешивающимися гидрофобным органическим растворителем и водным раствором, которая наиболее подходит для подготовки пробы при анализе методом нормально-фазовой ВЭЖХ, применяется существенно реже, чем ОФ ВЭЖХ. Добавка более гидрофильного растворителя к гидрофобному всегда приводит к синергетическому эффекту - в смешанных экстрагентах эффективность извлечения полифункционального аналита выше [6]. MeCN в этом случае может быть использован в качестве минорной добавки в неполярный экстрагент. Дополнительный фактор, повышающий эффективность концентрирования методом ЖЖЭ - применение высаливания [6,30,33,34] или высахаривания [30]. В этом случае даже гидрофильный МeCN расслаивается с водным раствором, что позволяет его успешно применять в качестве экстрагента[6,30,41]. Для улучшения экстракционной способности гидрофильного экстрагента на основе МeCN по отношению к гидрофобным соединениям, его можно смешивать с менее полярным компонентом (простыми или сложными эфирами, кетонами), имеющими большее химическое сродство к гидрофобным соединениям, сохранив при этом способность расслаиваться при внесении в водный раствор солей или углеводов.

Не только $\mathrm{MeCN}$, но и такие растворители как ацетон, диоксан, пропиловые спирты, 4-бутиролактон, $\mathrm{N}$-метилпирролидон, трет-бутиловый спирт, диацетоновый спирт могут в присутствии высаливателей образовывать самостоятельную водно-органическую фазу, в которой содержится от 2 до 50\% воды[6]. Это свойство используют в гидрофильной ЖЖЭ. В качестве высаливателей хорошо себя зарекомендовали $(\mathrm{NH})_{2} \mathrm{SO}_{4}$ и $\mathrm{Li}_{2} \mathrm{SO}_{4}$, хотя используют и другие соли, например, $\mathrm{K}_{2} \mathrm{HPO}_{4}$, $\mathrm{KH}_{2} \mathrm{PO}_{4}, \mathrm{MgSO}_{4}, \mathrm{NaCl}$. Варьируя концентрацию и тип высаливателя можно изменять соотношение органического растворителя и воды в двух разделенных фазах. Если концентрация высаливателя в водном растворе приближается к насыщению, то содержание органического растворителя в водной фазе стремится к минимуму. Образованию гетерогенной системы способствует сочетание применения солей и охлаждения до $4^{\circ} \mathrm{C}$.

Высахаривание применяют, прежде всего, в фармацевтическом анализе и фармацевтических технологиях [42]. Для расслоения ацетонитрильной фазы от водной в качестве высахаривающих агентов использовали глюкозу, фруктозу, сахарозу и другие моно- и дисахариды [41,42]. Моно- и дисахариды образуют ажурные меж- 
молекулярные структуры с водой, благодаря формированию водородных связей, которые способствуют расслоению с ацетонитрильной фазой. Оптимальная концентрация углевода в экстракционной системе - 50 г/дм ${ }^{3}$ [42]. Растворимые олиго- и полисахариды, тем не менее, не проявили ожидаемых эффектов высахаривания, что требует еще научной интерпретации.

При ЖЖЭ органических соединений, имеющих как гидрофобные, так и гидрофильные фрагменты использование гидрофильных экстрагентов приводит к синергетическому эффекту от увеличения воды в экстрагенте. На Рис. 8 приведена диаграмма зависимости коэффициентов D от содержания $\mathrm{MeCN}$ в органической фазе и гидрофобности фенолов. Максимальное извлечение фенолов наблюдали при $30 \%$ об. содержании воды в экстрагенте, при этом более гидрофобные фенолы извлекаются из водно-солевого раствора в водно-органическую фазу эффективней. Наоборот, при приближении концентрации $\mathrm{MeCN}$ к $100 \%$ уменьшается его химическое сродство к гидроксилсодержащему фенольному соединению и коэффициент D уменьшается.

Привлекательным для гидрофильной ЖЖЭ, как и для ВЭЖХ, является азеотропная смесь ацетонитрила с водой (84:16), которая образуется при добавлении $17.5 \%\left(\mathrm{NH}_{4}\right)_{2} \mathrm{SO}_{4}$ в водную пробу. Эта смесь с практической точки зрения интересна тем, что легко регенерируется для многократного применения. В настоящее время выделение в лабораторных условиях чистого $\mathrm{MeCN}$ из азеотропной смеси с водой экономически не выгодно. Однако перспективным способом разрушения азеотропной системы $\mathrm{MeCN}$ - вода является применение некоторых ионных жидкостей [7].

Взаимная растворимость МеCN и воды сильно зависит от температуры. Данные, представленные в работах [6,10-13,30] показывают, что смеси МеCN - вода при хранении в течение от получаса до нескольких часов при температуре ниже комнатной расслаиваются на две жидкие фазы. Разделение фаз происходит при температуpax ниже $-1.32^{\circ} \mathrm{C}$ и может наблюдаться в широком диапазоне концентраций $\mathrm{MeCN}$ $\left(\varphi_{2}=0.31-0.89\right)$ [6]. Диапазон содержания $\mathrm{MeCN}$ в смесях с водой, способных расслаиваться при температуре около $-10^{\circ} \mathrm{C}$, уже ( $\varphi_{2}$ от 0.38 до 0.87$)$, тем не менее, и в этом случае можно подбирать состав растворителя пробы максимально близкий к составу подвижной фазы. При температурах $\leq-10{ }^{\circ} \mathrm{C}$ расслоение на две фазы происходит достаточно быстро ( $\leq 30$ мин), что применимо для рутинного анализа. В этих гетерогенных системах МеCN неравномерно распределен между двумя фазами. Верхняя фаза обогащена $\mathrm{MeCN}$, а нижняя фаза - водой. Это свойство МeCN используют для подготовки проб образцов, в том числе для депротеинизации сырого образца, удаления белка из органического растворителя, для селективной ЖЖЭ фенолов, триклозана, бисфенола А из сложных смесей, например, из молочных продуктов. Это явление может использоваться также как криометод удаления избытка $\mathrm{MeCN}$ из биологических образцов и из хроматографических подвижных фаз [6,10-15,30-32].

Образование двухфазной гетерогенной системы жидкость - жидкость для смесей МeCN с водой при низкой температуре, безусловно, представляет большой практический интерес с точки зрения использования этого явления для подготовки проб в химическим анализе методом ОФ ВЭЖХ, так как $\mathrm{MeCN}$ является базовым растворителем для подвижных фаз в этом варианте ВЭЖХ. Особенно это важно для анализа лабильных БАВ, метаболитов, выделяемых из биологических жидкостей. В работах [6,9-11] показана возможность применения МеCN для реализации низкотемпературной ЖЖЭ фенолов из водных проб. 


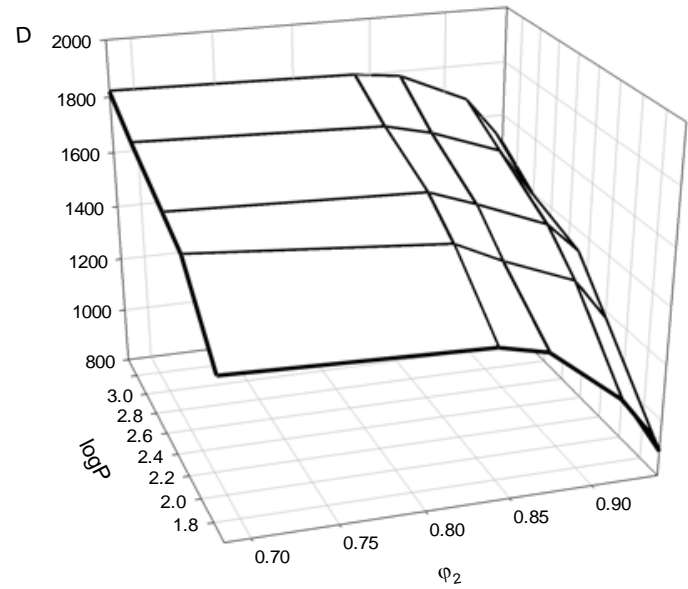

Рис. 8. Зависимость коэффициента распределения фенолов от их гидрофобности и объёмной доли МеCN в органической фазе. Высаливатель $\left(\mathrm{NH}_{4}\right)_{2} \mathrm{SO}_{4}$ [6]

$\mathrm{MeCN}$ имеет хорошую солюбилизирующую способность для многих органических аналитов, однако он сравнительно слабо растворяет при охлаждении многие соединения, отличающиеся высокой гидрофобностью, например, некоторые антиоксиданты и стабилизирующие добавки фенольного типа. Поэтому для улучшения растворимости таких аналитов в ацетонитрильной фазе при реализации низкотемпературной ЖЖЭ можно использовать добавки к МеСN этилацетата и ИПС [10]. Так, в качестве перспективного экстрагента фенолов методом холодной ЖЖЭ является смесь $\mathrm{MeCN}$ - ИПС - этилацетат (80:5:15), в которой образование двухфазной системы жидкость-жидкость происходит за короткое время ( 10мин) выдерживания смеси при $-10^{\circ} \mathrm{C}$. Кроме увеличения солюбилизирующей способности ацетонитрильного экстрагента такие добавки уменьшают его токсичность и стоимость.

Метод QuEChERS. В 2003 г. S.J. Lehotay, M. Annastassiades [43] предложили метод QuEChERS для определения микроколичеств пестицидов в овощах и фруктах. Суть метода состоит в экстракции пробы водным МеCN или этилацетатом в присутствии высаливающего комплекса, очистке методом дисперсионной ТФЭ и хроматографическом анализе. В последнее время этим методом одновременно определяют не только остаточные содержания пестицидов, но и ветеринарных препаратов, природных токсинов в пищевом сырье с минимальными затратами, благодаря использованию на стадии пробоподготовки различных модификаций QuEChERS $[40,44]$. B этом методе для экстракции компонентов используют МeCN в присутствии буферирующих солей (цитратов натрия). Для очистки экстрактов от липидов, жиров и белков применяют насыпные сорбенты Bondesil-PSA, C18, графитированную сажу, ионообменные смолы и их комбинации. К современным достижениям в области развития QuEChERS для пробоподготовки комплексных матриц можно отнести дополнительную очистку экстрактов методом дисперсионной микро-ЖЖЭ, суть которой заключается в быстром впрыскивании в воду ацетонитрильного экстракта QuEChERS с добавленным в него органическим растворителем, не смешивающимся с водой [44]. В результате образуется эмульсия, что вследствие увеличения поверхности соприкосновения фаз повышает эффективность разделения компонентов. После центрифугирования для анализа используют выделившуюся органическую фазу. Благодаря этой простой в исполнении дополнительной стадии, требующей значительно меньших количеств органических растворителей по сравнению с классическими методами экстракции, возможно одновременное селективное хроматографическое определение множества компонентов пробы, включая пестициды, ветпрепараты, стимуляторы роста (соединения с эстрогенной активностью) и микотоксины [44]. 
Экстракционное вымораживание. В работах [36-39] показано, что $\mathrm{MeCN}$ применим в режиме экстракционного вымораживания. При образовании фазы льда из воды при $-19 \div-20{ }^{\circ} \mathrm{C}$ органические вещества (искомые аналиты или мешающие примеси) вытесняются в жидкую ацетонитрильную фазу. Такой способ концентрирования и подготовки пробы активно применяют в ВЭЖХ в способе, получившем название liquid-liquid extraction with partition at low temperature (LLE-PLT). В измельченный образец добавляют несколько мл $\mathrm{MeCN}$, охлаждают до $-20{ }^{\circ} \mathrm{C}$, центрифугируют, отделяют органический слой, фильтруют и анализируют [36-39]. Этот метод заметно более дешевый, чем ТФЭ, поскольку нет необходимости использовать дорогие патроны с сорбентами. В работе Бехтерева В.Н. [36,45] показано, что экстракционное вымораживание является более эффективным методом концентрирования некоторых аналитов по сравнению с низкотемпературной ЖЖЭ.

\section{Заключение}

Ацетонитрил и его водные (буферные) смеси обладают уникальными хроматографическими и экстракционными свойствами, которые имеют важное прикладное значение. Учет зависимостей физико-химических свойств смесей ацетонитрила с водой от их состава позволяет найти оптимальные условия реализации хроматографических и экстракционных процессов с применением этих смесей. Для хроматографических и спектроскопических методов анализа является перспективным усовершенствование методик пробоподготовки аналитов с применением жидкостножидкостной экстракции с высаливанием, высахариванием, низкотемпературной жидкостно-жидкостной экстракции, экстракционного вымораживания и метода QuEChERS, в котором применяется гибридный подход в применении нескольких методов концентрирования.

\section{Список литературы}

1. Яшин А.Я., Веденин А.Н., Яшин Я.И. // Лаборатория и производство. 2018. № 1. C. $72-80$.

2. Схунмакерс П. Схунмакерс П. Оптимизация селективности в хроматографии. М. Мир. 1989. 399 с.

3. Рудаков О. Б., Востров И. А., Федоров С. В. и др. Спутник хроматографиста. Методы жидкостной хроматографии. Воронеж. «Водолей». 2004. 528 с.

4. Рудаков О.Б. Растворитель как средство управления процессом в жидкостной хроматографии. Воронеж. ВГУ. 2003. 300 с.

5. Садек П. Растворители для ВЭЖХ. М. Бином Лаборатория знаний. 2006. 704 с.

6. Хорохордина Е.А., Подолина Е.А., Рудаков О.Б. Жидкостная экстракция смешанными растворителями. Применение в химическом анализе фенолов. Saarbrücken. LAP Lambert Academic Publishing. 2012. 240 c.

7. McConvey I.F., Woods D., Lewis M., Gan Q., Nancarrow P. // Org. Process Res. Dev. 2012. Vol. 16. No 4. pp. 612-624.
8. Pence D.N., Tingyue Gu. // Separations Technology. 1996. Vol. 6. No 4. pp. 261-264.

9. Рудаков О.Б., Хорохордина Е.А., Преображенский М.А. // Журнал физической химии. 2017. Т. 91. № 4. С. 754-757.

10. Рудаков О.Б., Хорохордина Е.А., Преображенский М.А., Рудакова Л.В. // Журнал физической химии. 2016. Т. 90. № 8. С. 12571260.

11. Подолина Е.А., Рудаков О.Б., Тхинь Ф.В., Рудакова Л.В. // Журнал аналитической химии. 2010. Т. 65. № 2. С. 121-123.

12. Zarzycki P.K., Zarzycka M.B., Ślączka M.M. // Analytical and Bioanalytical Chemistry. 2010. Vol. 397. No 3. pp. 905-908.

13. Zhang Hongyi, Zhao Jieyu, Wu Zhibin, Wang Zichuan. International Conference on Agricultural and Natural Resources Engineering (ICANRE). Singapore, 2013. IERI Procedia. No 5. pp. 277-283.

14. Рудакова Л.В., Рудаков О.Б. Информационные технологии в аналитическом 
контроле биологически активных веществ. С.-П. Лань..2015. 361 с.

15. Tingue $\mathrm{Gu}$, Yesong $\mathrm{Gu}$, Yizhou Zheng // Separations Technology. 1994. Vol. 4. No 4. pp. 258-260.

16. Рудаков О.Б., Соколов М.И., Рудакова Л.В. // Журнал физической химии. 1999. Т. 73. № 7. С. 1303-1306.

17. Рудакова Л.В., Рудаков О.Б., Барсукова Л.Г., Кривнева Г.Г. // Сорбичонные и хроматографические прочессы. 2012. Т. 12. № 4. С. 547-553.

18. Рудаков О.Б., Соколов М.И., Селеменев В.Ф. // Журнал физической химии. 1999. Т. 73. № 9. С. 1641-1644.

19. Преображенский М.А., Рудаков О.Б., Кривнева Г.Г. и др. // Сорбичионные и хроматографические прочессы. 2013. Т. 13. № 3. С. 298-306.

20. Рудаков О.Б., Рудакова Л.В., Подолина Е.А., Барсукова Л.Г. // Журнал физической химии. 2009. Т. 83. № 11. С. 1972-1975.

21. Рудаков О.Б., Селеменев В.Ф. // Журнал физической химии. 1999. Т. 73. № 12. С. 2242-2245.

22. Openhaim G., Grushka E. // Journal of Chromatography. 2002. Vol. 942. No 1-2. pp. 63-71.

23. Рудаков О.Б., Хрипушин В.В., Бочарова О.Н., Рудакова Л.В. // Журнал аналитической химии. 2001. Т. 56. № 1. С. 44-51.

24. Преображенский М. А., Рудаков О.Б., Рудакова Л.В., Попова М.И. // Научный Вестник ВГАСУ. Серия: Физико-химические проблемы и высокие технологии строительного материаловедения. 2015. № 11. С. 8089.

25. Rowlen K.L., Harris J.M. // Analytical Chemistry. 1991. Vol. 63. No 10, pp. 964-969.

26. Рудаков О.Б., Бочарова О.Н. // Журнал физической химии. 2000. Т. 74. № 6. С. 10591064.

27. Reichardt C., Welton T. Solvents and Solvent Effects in Organic Chemistry. 4th, upd. and enlarg. Ed. Wiley-VCH. 2011. 711 p.

28. Рудаков О.Б., Седишев И.П. // Известия РАН. Серия химическая. 2003. Т. 52. № 1. С. 52-59.

29. Рудаков О.Б., Рудакова Л.В. // Сорбичионные и хроматографические прочессы. 2012. T. 12. № 2. С. 231-239.
30. Yesong $\mathrm{Gu}$, Po-Huhg Shih. // Enzyme and Microbial Technology. 2004. Vol. 35. № 67, pp. 592-597.

31. Roach A., Dunlap J., Harte F. // Journal of Food Science. 2009. Vol.74. No 2. pp. 23-29.

32. Georgescu B., Georgescu C.E. // Animal Biology \& Animal Husbandry. International Journal of the Bioflux Society. 2013. Vol. 5. No 2. pp.171-174.

33. Подолина Е.А., Рудаков О.Б., Хорохордина Е.А., Григорьев А.М. // Журнал аналитической химии. 2008. Т. 63. № 6. С. 599602.

34. Рудаков О.Б., Хорохордина Е.А., Подолина Е.А., Харитонова Л.А. // Журнал физической химии. 2007. Т. 81. № 12. С. 22782283.

35. Sudipta S., Ashok K.S., Amit K.K. et al. Modern Extraction Techniques for Drugs and Medicinal Agents. Ingredients extraction by physicochemical methods in food. Handbook of Food Bioengineering, 2017. No. 4. pp. 65-106.

36. Бехтерев В.Н. // Журнал аналитической химии. 2011. Т. 66. № 6. С. 608-613.

37. De Pinho G.P., Neves A. A., de Queiroz M. E. L.R. et al. // Food chemistry. 2010. Vol. 121. No 1. pp. 251-256.

38. De Pinho G. P., Neves A. A., de Queiroz M.E.L.R. et al. // Food control. 2010. Vol. 21. No 10. pp. 1307-1311.

39. Goulart, S. M., de Queiroz, M. E. L.R., Neves A.A. et al. // Talanta. 2008. Vol. 75. No 5. pp. 1320-1323.

40. Rahman M.M., Abd El-Aty A.M., Kim S.-W. et al. // Journal of separation science. 2017. Vol. 40. No 1. pp. 203-212.

41. Wang B., Ezejias T., Hao Feng, Blaschek H. // Chemical Engineering Science. 2008. Vol. 63. No 9. pp. 2595-2600.

42. Nugbienyo L., Malinina Y., Garmonov S. et al. // Talanta. 2017. Vol. 167. pp. 709-713.

43. Anastassiades M., Scherbaum E., Bertsch D. MGPR Symposium. May 2003. Aix en Provence. France. 2003. p.7.

44. Амелин В.Г., Лаврухина О.И. // Журнал аналитической химии. 2017. Т. 72. № 1. C. 3-49.

45. Бехтерев В.Н. // Журнал физической химии. 2016. Т. 90. № 10. С. 1558-1562. 


\section{References}

1. Yashin A.Ya., Vedenin A.N., Yashin Ya.I., Laboratoriya i proizvodstvo, 2018, No 1, pp.7280.

2. Schoenmakers P.J., Optimization of chromatographic selectivity. A guide to method development (Journal of Chromatography Library Vol. 35), Amsterdam, Oxford, New York, Tokyo, Elsevier, 1986, 345 p.

3. Rudakov O.B., Vostrov I.A., Fedorov S.V., Filippov A.A. et al., Sputnik khromatografista. Metody zhidkostnoi khromatografii (Methods of Liquid Chromatography. Handbook), Voronezh, Vodoley, 2004, 528 p. (in Russian)

4. Rudakov O.B. Rastvoritel' kak sredstvo upravleniya protsessom $v$ zhidkostnoy khromatografii (Solvent as a means of controlling the process in liquid chromatography). Voronezh, VGU, 2003, 300 p.. (in Russian)

5. Sadek P.C. The HPLC solvent guide. 2nd Edition, John Wiley and Sons, Inc., 2002, 664 p.

6. Khorokhordina E.A., Podolina E.A., Rudakov O.B., Zhidkostnaya ekstraktsiya smeshannymi rastvoritelyami. Primeneniye $v$ khimicheskom analize fenolov (Liquid extraction with mixed solvents. Application in the chemical analysis of phenols), Saarbrücken. LAP Lambert Academic Publishing, 2012, 240 p. (in Russian)

7. McConvey I.F., Woods D., Lewis M., Gan Q. et al., Org. Process Res. Dev., 2012, Vol.16, No 4, pp. 612-624. DOI: 10.1021/op2003503

8. Pence D.N., Tingyue Gu. Separations Technology, 1996, Vol. 6, No 4, pp. 261-264. DOI: 10.1016/S0956-9618(96)00161-0

9. Rudakov O.B., Khorokhordina E.A., Preobrazhenskii M.A. Russian Journal of Physical Chemistry, 2017, Vol. 91, № 4, pp. 754-757. DOI: $10.1134 / \mathrm{S} 0036024417040240$

10.Rudakov O.B., Khorokhordina E.A., Preobrazhenskii M.A., Rudakova L.V., Russian Journal of Physical Chemistry, 2016, Vol. 90, No $8, \quad$ pp. 1665-1668. DOI: 10.1134/S0036024416080264

11.Podolina E.A., Rudakov O.B., Thin F.V., Rudakova L.V. Journal of Analytical Chemistry, 2010, Vol. 65, No 2, pp. 117-119. DOI: 10.1134/S1061934810020036

12.Zarzycki P.K., Zarzycka M.B., Ślączka M.M., Analytical and Bioanalytical Chemistry, 2010, Vol. 397, No 3, pp. 905-908. DOI: 10.1007/s00216-010-3677-9

13.Zhang Hongyi, Zhao Jieyu, Wu Zhibin, Wang Zichuan, International Conference on
Agricultural and Natural Resources Engineering (ICANRE). Singapore, SINGAPORE, May 01-02, 2013, IERI Procedia, Vol. 5, pp. 277283. DOI: 10.1016/j.ieri.2013.11.104

14. Rudakova L.V., Rudakov O.B., Informatsionnyye tekhnologii $v$ analiticheskom kontrole biologicheski aktivnykh veshchestv (Information technology in the analytical control of biologically active substances), St. Petersburg, Lan'., 2015, 361 p. (in Russian)

15.Tingue $\mathrm{Gu}$, Yesong $\mathrm{Gu}$, Yizhou Zheng, Separations Technology, 1994, Vol. 4, No 4, pp. 258-260. DOI: 10.1016/0956-9618(94)80031-6

16.Rudakov O.B., Sokolov M.I., Rudakova L.V., Russian Journal of Physical Chemistry, 1999, Vol. 73, No 7, pp. 1165-1168.

17.Rudakova L.V., Rudakov O.B., Barsukova L.G., Krivneva G.G., Sorbtsionnyye i khromatograficheskiye protsessy, 2012, Vol. 12, No 4, pp. 547-553 (in Russian)

18.Rudakov O.B., Sokolov M.I., Selemenev V.F. Russian Journal of Physical Chemistry, 1999, Vol. 73, No 9, pp. 1473-1476.

19.Preobrazhensky M.A., Rudakov O.B., Krivneva G.G., Barsukova L.G. et al., Sorbtsionnyye i khromatograficheskiye protsessy, 2013, Vol. 13, No 3, pp. 298-306 (in Russian)

20. Rudakov O.B., Rudakova L.V., Podolina E.A., Barsukova L.G., Russian Journal of Physical Chemistry, 2009, Vol. 83, No 11, pp. 19721975. DOI: $10.1134 / \mathrm{S} 0036024409110272$

21.Rudakov O.B., Selemenev V.F., Russian Journal of Physical Chemistry, 1999, Vol. 73, No 12, pp. 2019-2022.

22. Openhaim G., Grushka E., Journal of Chromatography, 2002, Vol. 942, No 1-2, pp. 63-71. DOI: 10.1016/ S0021-9673(01)01355-3

23.Rudakov O.B., Khripushin V.V., Bocharova O.N., Rudakova L.V., Journal of analytical chemistry, 2001, Vol. 56, No 1, pp. 36-42. DOI: 10.1023/A:1026763327616

24.Preobrazhensky M.A., Rudakov O.B., Rudakova L.V., Popova M.I. Nauchnyy Vestnik Voronezhskogo gosudarstvennogo arkhitekturno-stroitel'nogo universiteta. Seriya: Fizikokhimicheskiye problemy $i$ vysokiye tekhnologii stroitel'nogo materialovedeniya, 2015, No 11, pp. 80-89 (in Russian)

25. Rowlen K.L., Harris J.M., Anal. Chem., 1991, Vol. 63, No 10, pp. 964-969. DOI: 10.1021/ac00010a006 
26.Rudakov O.B., Bocharova O.N., Russian Journal of Physical Chemistry A, 2000, Vol. 74, No 6, pp. 974-979.

27. Reichardt C., Welton T., Solvents and Solvent Effects in Organic Chemistry. 4th, upd. and enlarg. ed., Wiley-VCH, 2011, 711 p.

28.Rudakov O.B., Sedishev I.P., Russian Chemical Bulletin, 2003, Vol. 52, No 1, pp. 5562. DOI: $10.1023 / \mathrm{A}: 1022475710649$

29.Rudakov O.B., Rudakova L.V., Sorbtsionnyye i khromatograficheskiye protsessy, 2012, Vol. 12, No 2, pp. 231-239. (in Russian)

30.Yesong Gu, Po-Huhg Shih., Enzyme and Microbial Technology, 2004, Vol. 35, No 6-7, pp. 592-597. DOI: 10.1016/j.enzmictec.2004.08.011

31.Roach A., Dunlap J., Harte F., Journal of Food Science, 2009, Vol. 74, No 2, pp.23-29. DOI: $10.1111 / \mathrm{j} .1750-3841.2009 .01048 . \mathrm{x}$

32.Georgescu B., Georgescu C.E., Animal Biology \& Animal Husbandry International Journal of the Bioflux Society, 2013, Vol. 5, No 2, pp.171-174.

33.Podolina E.A., Rudakov O.B., Khorokhordina E.A., Grigorev A.M., Journal of Analytical Chemistry, 2008, Vol. 63, No 6, pp. 548-550. DOI: $10.1134 / \mathrm{S} 1061934808060063$

34.Rudakov O.B., Khorokhordina E.A., Podolina E.A., Kharitonova L.A., Russian Journal of Physical Chemistry A, 2007, Vol. 81, No 12, pp. 2053-2058. DOI: $10.1134 / \mathrm{S} 0036024407120242$

35. Sudipta S., Ashok K.S., Amit K.K. et al., Modern Extraction Techniques for Drugs and Medicinal Agents. Ingredients extraction by physicochemical methods in food. Handbook of

Рудаков Олег Борисович - д.Х.н., зав. кафедрой химии и химической технологии материалов Воронежского государственного технического университета, Воронеж

Селеменев Владимир Федорович - д.Х.н., зав. кафедрой аналитической химии Воронежского государственного университета, Воронеж

Рудакова Людмила Васильевна - д.х.н., зав. кафедрой фармацевтической химии и фармацевтической технологии Воронежского государственного медицинского университета, Воронеж

Подолина Елена Алексеевна - д.х.н., профессор Государственного гуманитарнотехнологического университета, Орехово-Зуево
Food Bioengineering, 2017, Vol. 4, pp. 65-106. DOI: 10.1016/B978-0-12-811521-3.00002-8

36.Bekhterev V.N., Journal of Analytical Chemistry, 2011, Vol. 66, No 6, pp. 591-595. DOI: $10.1134 / \mathrm{S} 1061934811060025$

37.De Pinho G.P., Neves A.A., de Queiroz M.E.L.R. et al., Food chemistry, 2010, Vol. 121, No 1, pp. 251-256. DOI: 10.1016/j.foodchem.2009.11.080

38.De Pinho G.P., Neves A.A., de Queiroz M.E.L.R. et al., Food control, 2010, Vol. 21, No 10, pp. 1307-1311. DOI 10.1016/j.foodcont.2010.03.006

39.Goulart S.M., de Queiroz, M.E.L.R., Neves A.A. et al., Talanta, 2008, Vol. 75, No 5, pp. 1320-1323. DOI: 10.1016/j.talanta.2008.01.058

40.Rahman M.M., Abd El-Aty, A.M., Kim, S.-W. et al., Journal of separation science, 2017, Vol. 40, No 1, pp. 203-212 DOI: $10.1002 /$ jssc. 201600889

41.Wang B., Ezejias T., Hao Feng, Blaschek H. Chemical Engineering Science, 2008, Vol. 63, No 9, pp. 2595-2600. DOI :10.1016/j.ces.2008.02.004

42.Nugbienyo L., Malinina Y., Garmonov S., Talanta, 2017, Vol. 167, pp. 709-713 DOI: 10.1016/j.talanta.2017.02.051

43.Anastassiades M., Scherbaum E., Bertsch D., MGPR Symposium (May 2003, Aix en Provence, France), 2003, p.7.

44.Amelin V.G., Lavrukhina O.I., Journal of analytical chemistry, 2017, Vol. 72, No 1, pp. 146 DOI: $10.1134 / \mathrm{S} 1061934817010038$

45.Bekhterev V.N. Russian Journal of Physical Chemistry A, 2016, Vol. 90, No 10, pp. 2055-2059. DOI: $10.7868 /$ S0044453716100046

Rudakov Oleg B. - Dr. Sci (Chemistry), head of Department of chemistry and chemical technology of materials of Voronezh state technical University, Voronezh. E-mail: robi57@mail.ru

Selemenev Vladimir F. - Dr. Sci (Chemistry), head of Department of analytical chemistry of Voronezh state University, Voronezh. E-mail: common@chem.vsu.ru

Rudakova Lyudmila V. - Dr. Sci (Chemistry), head of Department of pharmaceutical chemistry and pharmaceutical technology of Voronezh state medical University, Voronezh. E-mail: vodoley65@mail.ru

Podolina Elena A. - Dr. Sci (Chemistry), Professor of State humanitarian and technological University, Orekhovo-Zuyevo. E-mail: podolina70@mail.ru 